\title{
Tangence
}

\section{Les bafoués}

\section{Paul Savoie}

Numéro 56, décembre 1997

Postures scripturaires dans la littérature franco-ontarienne

URI : https://id.erudit.org/iderudit/025961ar

DOI : https://doi.org/10.7202/025961ar

Aller au sommaire du numéro

Éditeur(s)

Tangence

ISSN

0226-9554 (imprimé)

1710-0305 (numérique)

Découvrir la revue

Citer ce document

Savoie, P. (1997). Les bafoués. Tangence, (56), 103-108.

https://doi.org/10.7202/025961ar d'utilisation que vous pouvez consulter en ligne.

https://apropos.erudit.org/fr/usagers/politique-dutilisation/ 


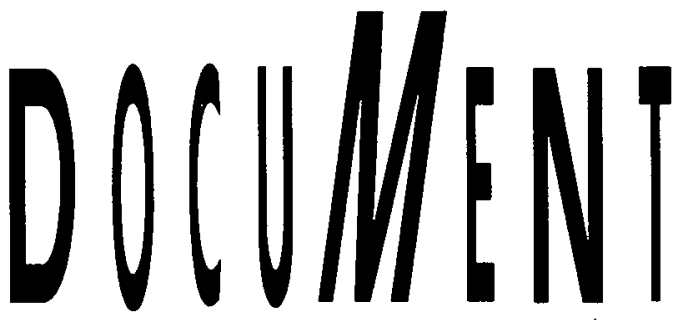

\section{Les bafoués}

Paul Savoie

Tout est question de rythme, de précision. Elle trace une ligne de sensation le long de sa manche verte, en tissu rude. Elle frôle légèrement la peau sèche, mise un peu à découvert par le décolleté en cœur. Elle se palpe le front, la joue. Elle se tient debout, raide, regarde devant elle tout en évitant le reflet du miroir, trop avide de grimaces.

Quelques coups de brosse encore, pour amadouer les mèches qui s'égarent. Un peu de poudre sur les joues. Le pinceau-traceur pour la petite ligne sombre à peine perceptible au bout des sourcils. Un rouge à lèvres pâle. Un peu de poudre à l'endroit des rides, au nom d'une certaine symétrie.

Elle se sent prête. Le prochain prétendant arrive dans quelques minutes. Elle aime plus que tout cette période d'avantgoût, semblable à l'attente fébrile devant l'ouragan qui, n'obéissant qu'à ses propres lois, en rituel de méchanceté vient tout déraciner.

Elle regarde sa montre. Deux minutes encore. Elle se rend devant le faux foyer, jette un regard furtif en direction du grand miroir entaché. Grâce à un jeu d'éclairage astucieux, la piècé, renvoyée en bribes vers elle, semble recouverte d'une toile diaphane. Les objets donnent une apparence de mobilité tout en étant désaxés, comme si quelqu'un faisait tourner la pièce à une vitesse infinitésimale.

Trente secondes encore. Dix. Cinq.

$\mathrm{Au}$ bruit de la sonnette, elle esquisse un sourire, qui presque aussitôt s'estompe. Elle avance de quelques pas, s'arrête: Elle a 
l'impression d'entendre l'homme respirer de l'autre côté de la porte, malgré l'épaisseur du bois. Elle écoute, se rend compte que l'homme ne respire pas, n'ose pas respirer. Il reste figé et attend.

Elle calcule. Encore dix secondes et le tour sera joué.

L'homme sonne à nouveau, doucement, comme lors des anciennes messes, lorsque l'acolyte faisait à peine tinter la cloche au moment de la communion, afin de ne pas briser l'air de recueillement. Elle glisse les pieds en avant et, bien positionnée, ouvre à peine la porte. Puis elle se retourne brusquement et retrace ses pas.

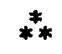

L'homme voit devant lui une porte entrebâillée. De l'obscurité soudaine qui s'offre à lui en grands rideaux soyeux, il entend une voix lui glisser à l'oreille: -Viens." Il pousse la porte, qui grince en frottant contre le plancher de bois franc. Il voit une longue chevelure flotter dans l'air épais de la pièce. Aussitôt, un bruissement se fait entendre, quelque chose d'amorti, peut-être le frou-frou d'un tissu fin, un frottement de pieds contre le tapis, un sifflement entre les feuillages. "Viens", il entend de nouveau. La voix vient de plus loin cette fois. Une voix grasse, trouée.

Il se trouve maintenant à l'intérieur de la pièce. Il essaye de se donner des points de repère mais il discerne mal les objets. Une odeur de poivre se propage dans la pièce, mêlée à celle du musc. Il a l'impression de grossir, à cause de l'ombre qui l'enveloppe soudainement, ou de s'enfoncer dans une matière visqueuse. Il a les poings tendus. Le cour bat trop rapidement.

"C'est un peu sombre *, offre-t-il en guise d'ouverture tout en s'avançant d'un pas et en tendant une main vers la forme indistincte devant lui. La femme, qui semble anticiper chacun de ses gestes, s'esquive. Elle se trouve maintenant dans une petite alcôve, où, assise à une table, elle verse du thé.

"J'ai préparé une tisane." La voix, plus ténébreuse maintenant, semble venir de très loin. On la croirait désincarnée, détachée des cordes vocales. La voix d'un fantôme. 
Il ne se souvient pas d'avoir bougé mais il se trouve maintenant à table, en face d'elle. La lueur des chandelles fait tout vaciller. Puis, venant de plus haut, un petit rayon stroboscopique, venant d'un pendentif, strie les visages de lueurs pâles. Le visage de la femme lui apparaît en images ciselées, en fragments de peau blanchâtre et de tissu céruléen qu'embrouillent l'incandescence des chandelles et les éclairs de safran qui surgissent à la hauteur de ses yeux. Tout tourne trop vite. L'homme a soudainement le vertige. Il essaye de se concentrer, ne trouve rien de mieux que de baisser les yeux. La main gauche pend inutilement à ses côtés.

La femme prononce quelques phrases à peine déchiffrables. L'homme s'accroche aux mots. Il n'a que cette voix pour le guider, qui lui commande maintenant de ne dire que la vérité. Mais, en même temps, elle insiste pour qu'il se taise.

Il parle en chuchotant. Il soulève sa tasse, la pose délicatement contre les lèvres, boit le plus lentement possible afin de ne rien brusquer. Il a l'impression que tout pèse dans la balance, qu'à cet instant précis, il doit faire preuve d'astuce s'il veut empêcher que tout bascule.

Il tourne la tête de droite à gauche. Il se mord les lèvres. Il répond intérieurement à plusieurs questions que quelqu'un a posées. Pourtant, il se trouve maintenant dans le silence le plus complet. Puis, ce qui le surprend, il n'arrive pas à compléter une seule phrase.

Il se souvient vaguement d'un être masqué, d'un mouvement de danse à l'intérieur de lignes concentriques bien marquées. Mais où se trouve le centre? Chaque geste, chaque nouveau mouvement semblent l'en éloigner.

Il cherche désespérément à récupérer quelque chose. Mais il se rend compte qu'il est désormais trop tard, que les quelques mensonges qu'il lui reste à proférer n'empêcheront pas l'enlisement au fond du gouffre.

Les hommes font la queue. Combien sont venus lui rendre visite? Elle ne le sait plus au juste. Elle a cessé depuis longtemps de les compter. 
106

Elle se moque de leur nom, de l'adresse et du numéro de téléphone qu'ils lui ont confiés. Ici, dès qu'ils franchissent le seuil de la porte, ils perdent tous leurs droits. Ils cessent du même coup d'avoir une identité. Elle leur enlève tout: leur visage, leur voix, leur histoire. Elle tire toutes les ficelles. Elle les défait de fond en comble.

Cet homme, trop bien coiffé, sent la menthe, ce qui lui donne la nausée. Elle se dit qu'il doit se raser plus d'une fois par jour, presser souvent ses pantalons, se faire chaque semaine une nouvelle provision de chemises et de cravates. Il est pincé jusqu'aux dents, avec les fesses qui serrent trop fort, l'étouffent par en dedans: Il est tout en dentelles, mais ne connaît que l'entortillement.

Celui-ci a peur de tout le monde. Il voudrait qu'on le sorte de lui-même, qu'on lui offre une bouée de sauvetage. Mais il ne saurait s'y agripper. Il est un habitué des naufrages. On n'a qu'à l'engloutir un peu plus, pour en finir avec la noyade.

Et cet autre, qui ne reste pas en place, souffre plus que tous parce qu'ici, il ne trouve que des surfaces, lui qui dessine déjà l'univers en traits rapides, sans profondeur. Comme tous les voyeurs, il réduit tout à des poses, à une série de gestes et de mouvements. Parce qu'elle élimine les contours, elle déjoue ses calculs. Il ne lui reste que des fragments, qu'il n'arrive pas à intégrer à son propre système de morcellement. 
Cet homme boit trop, mange trop. Il est quand même de la race des démunis, des dépossédés. Il n'a que sa détresse à offrir en gage. Il aspire tout. Il quête l'amour comme on cueille les mégots le long des trottoirs. Il provoque des sentiments de dégoût, mais aussi de pitié. On aimerait l'humilier, à même ses bourrelets, à même sa peau ondulante, comme une marée qui n'en finit plus de traîner la rive avec elle vers le large.

À chacun, elle impose le même rituel. Elle entraîne l'homme vers l'alcôve; il reste assis devant elle, incapable de bouger. L'illusion, qu'elle s'est donnée tant de peine à agencer, le tient dans sa toile et il n'arrive pas à s'en défaire. Elle laisse monter jusqu'à l'extrême limite la tension, jusqu'au point d'éclatement: L'homme ne prend jamais le dessus. Certains résistent plus longtemps que d'autres. Mais, à la fin, chaque homme, humilié au plus profond de lui-même, quitte la table la mine basse, en s'excusant bêtement et en prétextant un autre rendez-vous ou un malaise soudain. Par principe, elle ne raccompagne jamais son invité jusqu'à la porte.

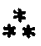

Elle épuise enfin sa liste. Plus personne ne vient. Plus personne ne viendra jamais. Elle en est presque soulagée.

L'homme qu'elle espérait ne s'est pas présenté. S'il existe, il a sûrement un nom, qu'elle lui prête maintenant, nom prononcé à voix basse.

Elle se souvient très bien de lui. Elle a toujours été étonnée devant la profondeur de son silence, qu'il porte en mots de passe, comme un miroir qui projette deux fois la même image.

Il a sa façon bien à lui de la contenir, de la rendre plus présente à elle-même qu'elle n'a jamais pu l'être.

Soudain, il est là. Elle le pressent.

Il arrive quinze minutes en retard, ce qui augure bien. Il ne sonne pas. Plutôt il frappe. Trois petits coups. Elle s'empresse de 
lui ouvrir la porte. Elle se trouve dans une noirceur opaque et lui, à cause de la lumière provenant du couloir, dans un cercle légèrement illuminé. Il a le dos courbé, marche en boitant un peu. À cause de la pluie, il porte un imperméable. Sa tête est recouverte d'un capuchon en plastique. D'épaisses lunettes cachent une partie du visage.

Il a le souffle lourd, haletant. Elle lui demande d'entrer, lui indique le canapé. Elle s'asseoit sur une berceuse en face de lui. Elle se recouvre les bras d'un châle.

Elle raconte tout, comme au confessional. Elle avoue qu'aucun homme n'a jamais su faire l'amour avec elle. Pas vraiment. Pourtant, elle le sait, elle est la plus belle d'entre toutes, même si personne n'est jamais venu jusqu'à elle. Elle demeure la plus sauvage, la moins connue.

Elle allume une cigarette dans le noir, se verse un verre de vin, sans en offrir à son visiteur.

Elle déplace soudainement sa main, posée à plat sur son genou. Et, pendant que les doigts tracent des lignes dans l'air, elle lui demande de faire l'amour avec elle.

Il répond tristement: "Mais je ne vous connais pas. Je ne vous vois pas."

Elle lui explique que lui seul saura percer l'opacité, se frayer un chemin en elle.

*Je ne sais rien de vous *, répond-il d'une voix presque rassurante, sans aigreur.

Elle soulève le bras, tend la main vers lui. Elle ressent une autre présence, lointaine, comme une brise soudaine écarte un rideau pendant un instant et laisse voir un paysage incertain, que des rayons de lune, en déviant sur une eau trouble d'un lac, dessinent sur la surface. Elle sent monter en elle un désir obscur, un déchirement. profond.

La femme se lève, s'approche de l'homme, qui semble distrait. Elle se souvient de quelqu'un, de quelque chose.

Il demeure parfaitement immobile.

Elle tend le bras.

Les doigts frôlent le vide. 